J. Clin. Chem. Clin. Biochem.

Vol. 16, 1978, pp. 557-560

\title{
Analysis of the Iron-Binding Sites of Transferrin by Isoelectric Focussing
}

By H. G. van Ë̈k, W. L. van Noort, M. J. Kroos and C. van der Heul

Department of Chemical Pathology, Medical Faculty, Erasmus University, Rotterdam, The Netherlands

(Received May 19, 1978)

\section{Summary:}

1. Human transferrin was labelled with ferric nitrilotriacetate (FeNTA) at one of its two metal binding sites by variation of the $\mathrm{pH}$.

2. Four transferrin forms, transferrin, transferrin(Fe) (A-site), transferrin(Fe) (B-site) and transferrin(2Fe) could be separated on flat bed gels by isoelectric focussing.

3. Incubation time, temperature and medium play an important role in the specificity of the binding of Fe. In NTApH-buffer, at $0.5 \mathrm{Fe}$-saturation, the A-site was preferentially labelled at pH 7-8, the B-site at a pH 8-9.

4. Under physiological conditions iron from the B-site has the tendency to move to the A-site.

\section{Untersuchung der Eisen-Bindungsstellen von Transferrin durch isoelektrische Fokussierung}

\section{Zusammenfassung:}

1. Transferrin vom Menschen wurde durch Variation des $\mathrm{pH}$ an einer seiner beiden Metall-Bindungsstellen mit Hilfe von Eisen(III)-nitrilotriacetat (FeNTA) markiert.

2. Durch isoelektrische Fokussierung auf Flachbettgelen konnten vier Transferrinformen getrennt werden: Transferrin, Transferrin(Fe) (Bindungsstelle A), Transferrin(Fe) (Bindungsstelle B) und Transferrin(2Fe).

3. Für die Spezifität der Eisenbindung spielen Inkubationszeit, -temperatur und -medium eine bedeutende Rolle. In NTA-pH-Puffer mit 0,5 Eisensättigung wurde die Bindungsstelle A vorzugsweise bei pH 7-8, Bindungsstelle B bei pH 8-9 markiert.

4. An der Bindungsstelle $B$ gebundenes Eisen hat unter physiologischen Bedingungen die Tendenz, zur Bindungsstelle A zu wandern.

\section{Introduction}

Transferrin is a $\beta$-globulin responsible for carrying iron in the blood (1). This protein has a $M_{r}$ of 80,000 , consists of a single polypeptide chain and has two metal binding sites. There is a considerable conflicting and contradictory literature $(2-10)$ concerning the equivalence or non-equivalence of the two binding sites (called A- and B-sites) and the hypothesis of Fletcher \& Huehins (1967) that the two molecules of iron bound to tranşerinin fulfil different physiological roles. The results of 10 years investigation on this point seems to be contradictory, probably mainly due to the fact that not even two of these ivestigations were performed under equivalent conditions. Makey et al (11) reported in 1976 the separation of 4 forms of transferrin in polyacrylamide gel electrophoresis in $6 \mathrm{~mol} / \mathrm{l}$ urea.
Their promising results prompted us to study these transferrin forms by electrophoresis in a medium not containing the denaturating agent urea.

For this purpose the very elegant flat bed isoelectric focussing method in polyacrylamide can be used as añalytical tool.

\section{Material and Methods}

Human transferrin (Kabi, Sweden) was used without further purification.

Iron free transferrin, apotransferrin, was made as described earlier (12).

FeNTA, $80 \mathrm{mg} \mathrm{Fe} \mathrm{O}_{3}$ was dissolved in $40 \mathrm{ml} 0.1 \mathrm{~mol} / 1 \mathrm{NTA}$ by boiling for 30 minutes. After cooling the solution was centrif- 
uged 5 minutes to spin down the brown undissolved material. The clear vellow supernatant was brought to $\mathrm{pH} 8$ with $0.1 \mathrm{~mol} / 1 \mathrm{Na}_{3} \mathrm{NTA}$ und diluted with $0.1 \mathrm{~mol} / 1$ sodium NTA-pHbuffer $\mathrm{pH}=8$ until the iron concentration was $3 \mathrm{mmol} / 1 \mathrm{Fe}$.

A NTA-pH-buffer was made by titration of $0.1 \mathrm{~mol} / 1 \mathrm{Na}_{3} \mathrm{NTA}$ with $0.1 \mathrm{~mol} / 1 \mathrm{NTA}$ until the desired $\mathrm{pH}$ was obtained.

$N T A$, nitrilotriacetic acid and its trisodium salt were obtained from Sigma.

Phosphate Buffered Saline was made by dissolving two tablets (Oxoid Ltd., England) per $100 \mathrm{ml}$ dist. water.

Iron binding to transferrin at different $\mathrm{pH}$

To the NTA-buffer at the desired $\mathrm{pH}$, apotransferrin solution was added so that the concentration was $6 \mathrm{~g} / \mathrm{l}$. If necessary the $\mathrm{pH}$ was corrected with the same acid or salt with an accuracy of $\mathrm{pH}$ measurement better than $0.05 \mathrm{pH}$.

FeNTA was then added according to the degree of saturation desired. This never changed the $\mathrm{pH}$ more than 0.05 .

Time and temperature of incubation are given in the legends to the figures.

The polyacrylamide gel was made and the focussing procedure was carried out in general as described in the Application Notes 75 and 306 (LKB, Sweden) with a few exceptions. Instead of acrylamide and bisacrylamide we used a factory-mixed chemical named Cyanogum-41 (Fisher Sci. Co), concentration $60 \mathrm{~g} / \mathrm{l}$.

Furthermore the gel contained $120 \mathrm{~g} / 1$ sucrose, $20 \mathrm{~g} / 1$ Ampholine pH 5-7 (LKB 1809-121) and the prescribed quantity of riboflavin. Polymerisation was stimulated by two TL-tubes $20 \mathrm{~W} / 50$ de Luxe Lights, (Philips, the Netherlands) overnight at a distance of $10 \mathrm{~cm}$.

Isoelectric focussing was carried out with the Multiphor (LKB 2117 , Sweden). Constant cooling was obtained by the use of a thermostated bath $\left(10^{\circ} \mathrm{C}\right)$. The gel was prefocussed for 60-90 minutes. Then $5 \mu$ l of each sample were applied with $5 \mu \mathrm{l}$ capillaries as a streak of about $0.4 \times 0.8 \mathrm{~cm}$ directly onto the gel surface $1 \mathrm{~cm}$ from the cathode. The voltage was preset at a maximum of $1200 \mathrm{~V}$ (DC power supply $2103, \mathrm{LKB}$ ).

The current and power were preset at maxima of $50 \mathrm{~mA}$ and 30 Watt respectively. When smaller gels were used, current and power were reduced proportionally. The optimal time for focussing appeared to be 3 hours (prefocussing time excluded).

Staining, after focussing the gel was directly stained with Coomassie Brilliant Blue G250, (Serva, Heidelberg, Germany) prepared according to Blakesley et al (13). Iron-specific staining was carried out with Nitroso-R-salz (Merck) according to Smith (14).

The position in the gels of apotransferrin and transferrin $(2 \mathrm{Fe})$ was determined in an isoelectric focussing experiment with these 2 proteins samples applied separately to the gels.

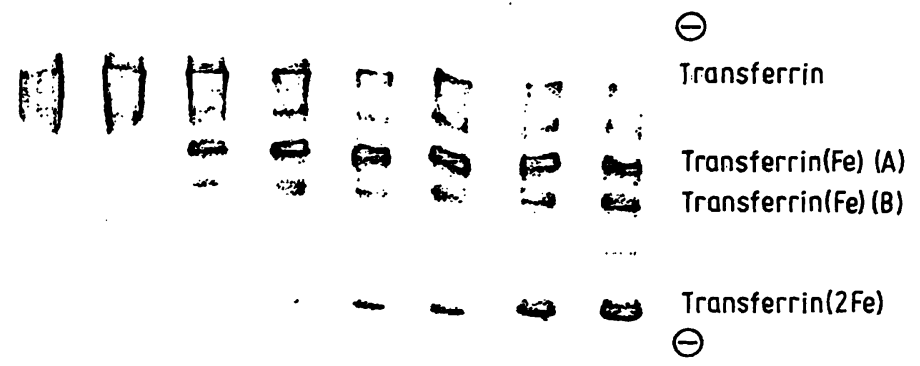

$\begin{array}{lllllllll}6.7 & 7.0 & 7.5 & 8.0 & 8.3 & 8.4 & 8.6 & 9.1 & \mathrm{pH}\end{array}$

Fig. 1. Transferrin, labelled with $\mathrm{Fe}$ to 0.5 saturation in a phosphate buffered saline-solution was separated into 4 main fractions, apotransferrin (left, low pH) two monoferric transferrins, labelled at the $\mathrm{A}$ - and $\mathrm{B}$-site and diferric transferrin.

\section{Results}

When transferrin was half saturated with FeNTA in a phosphate buffered saline solution at different $\mathrm{pH}$ values during 20 hours at $22^{\circ} \mathrm{C}$, the results shown in figure 1 were obtained. At $\mathrm{pH} 6.7$ and 7.0 mainly apotransferrin appears; evidently iron is not taken up by transferrin. At $\mathrm{pH}=7.5-9$ we see a distinct monoferric transferrin band (A-band) and also a second faint monoferric transferrin band (B-band). Gradually more diferric transferrin appears. In the $\mathrm{pH}$ range between 7.5-9, and in the presence of phosphate ions, the iron label is mainly at the A-site.

In a NTA-buffer the results are slightly different (fig. 2). At half saturation and a $\mathrm{pH}$ lower than 7.1 mainly apotransferrin is observed. At a pH between 7.1 and 8.1 the A-band of monoferric transferrin predominates, while at a pH 8.1-10 the B-band of monoferric transferrin, in contrast with the results in phosphate buffered saline, increases, together with the diferric transferrin band. Meanwhile the intensity of the A-band decreases.

From figure 3 the results of different degrees of saturation, varying between 0.20 and 1.00 and at $\mathrm{pH}$ values of

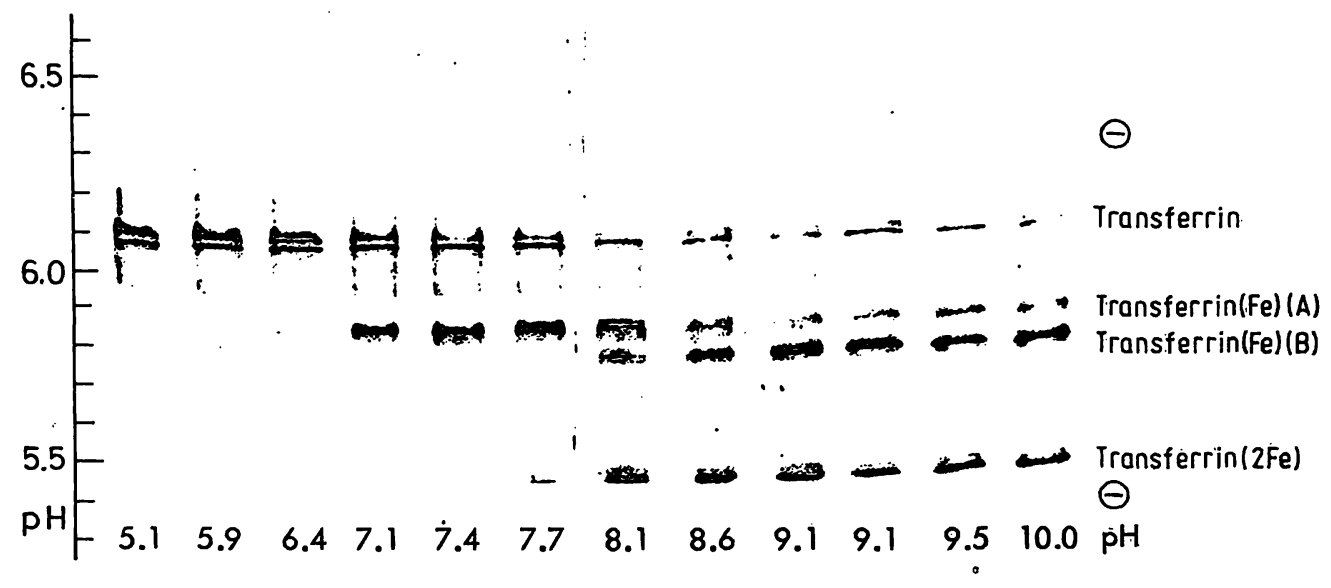

Fig : 2. Transferrin labelled with $\mathrm{Fe}$ to 0.5 saturation in a NTA= buffer was separated into 4 main fractions, apotransferrin (left, low pH) two monoferric transferrins and diferric transferrin. 


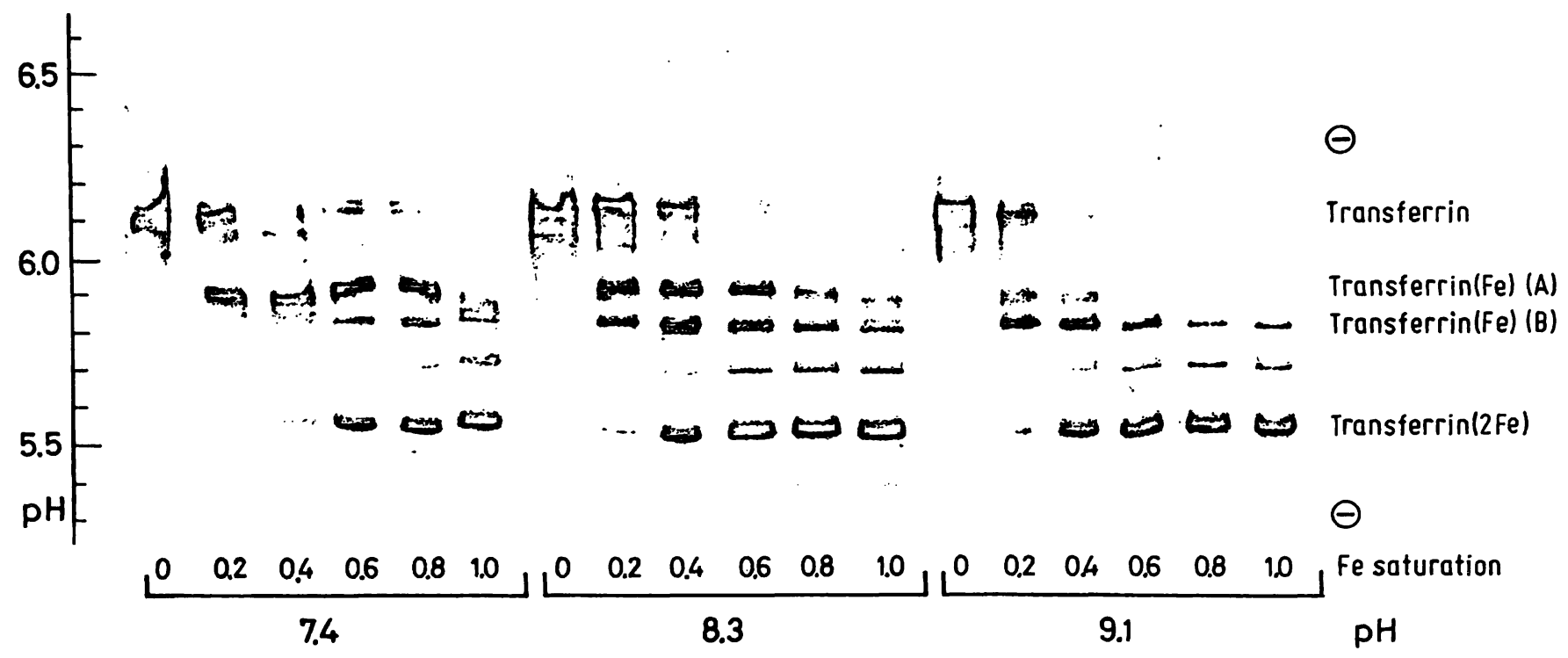

Fig. 3. Transferrin labelled with Fe to various degrees of saturation at pH 7.4 (mainly A-site monoferric) at pH 8.3 (A-and B-site monoferric) and 9.1 (mainly B-site monoferric).

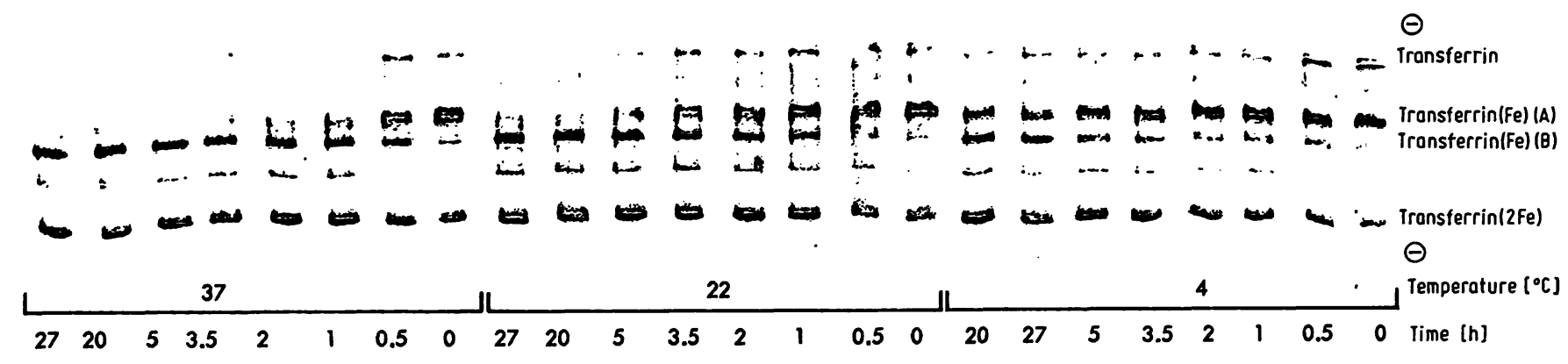

Fig. 4. Transferrin labelled with Fe to 0.5 saturation at pH 9 in NTA-buffer, showing the effect of variation in temperature (4, 22 and $37^{\circ} \mathrm{C}$ ) and time of incubation (0-27 hours).

7.4, 8.3 and 9.1 can be seen. At $\mathrm{pH} 7.4$ with a saturation degree of $0.20-0.80$, mainly the A-site of transferrin is occupied; at $\mathrm{pH}=8.3$ a higher intensity of the B-site can already be seen at a saturation degree of 0.20 , while at $\mathrm{pH}=9.1$, even with a saturation degree of 0.20 or 0.40 mainly the B-site is occupied.

From the electrophoretic pattern in figure 4 we can see how, at 0.50 saturation in a NTA-buffer, the complex formation, i. e. the formation of monoferric transferrin with $\mathrm{Fe}$ at the $\mathrm{A}$ - or B-site, is dependent on the time and temperature at which apotransferrin is incubated with FeNTA at $\mathrm{pH}=9$.

At $\mathrm{pH}=9$ and at $4{ }^{\circ} \mathrm{C}$ (at this $\mathrm{pH}$ most of the iron should bind to the B-site) the iron is mainly bound at site $A$ during the first 5 hours of incubation; later the iron is also bound to site B ( 20 and 27 hours).

At $22{ }^{\circ} \mathrm{C}$, after 2 hours of incubation, there is already more iron at the B-site, after 20 hours iron is nearly exclusively bound at the B-site and appears also as diferric transferrin.
At $37^{\circ} \mathrm{C}$, after 0.5 hour iron is already bound at the B-site and after 3.5 hours exclusively at the B-site and not at the A-site.

Most of the gels were also stained with the specific iron stain. The pictures confirm, with respect to transferrin $(\mathrm{Fe})$ and transferrin $(2 \mathrm{Fe})$, the results obtained with the Coomassie Blue stain.

\section{Discussion}

When Fe, in the form of FeNTA is added to a solution of human apotransferrin, the typical pink color of the iron-transferrin-anion complex appears immediately, but at which site the iron is bound cannot be determined spectroscopically.

FeNTA is a very common iron donor for labelling transferrin. From the results, as shown in figure 1, we can draw the conclusion that specific labelling at the B-site at higher $\mathrm{pH}$ in phosphate buffered saline is not 
possible. For this reason we looked for other buffers. Ampholine gave good results, but since FeNTA was the iron donor we changed to a NTA/Na $\mathrm{Na}_{3} \mathrm{NTA}$-buffer for the incubations. In this buffer below pH 7.7, mainly the A-site in monoferric transferrin was labelled; above $\mathrm{pH} 8.1$, the monoferric B-site transferrin appears. From figure 3 can be concluded that at a saturation of $0.40-0.60$ at pH 7.4 most of the A-site is occupied; at $\mathrm{pH} 9.1$ most of the B-site is occupied and at $\mathrm{pH} 8.3 \mathrm{a}$ random distribution over A- and B-sites occurs. However, a careful inspection of the pictures in figure 4 shows that even at $\mathrm{pH} 9$ at half saturation the binding always occurs first at the A-site, then at the B-site later in the incubation: the higher the temperature of incubation the earlier the change from A- to B-site.

The results suggest that the labelling occurs always via the A-site. Our electrophoretic analyses and conclusions are in agreement with the results of Canon et al (15) with EPR spectra of monoferric transferrin prepared at a different $\mathrm{pH}$. Our degrees of saturation are theoretical. In cases of 1.00 saturation a small amount of monoferric transferrin is still present; this is probably due to

\section{References}

1. Aisen, P. \& Brown, E. B. (1977), Sem. Haematol. 14, 3153.

2. Fletcher, J. \& Huehns, E. R. (1968), Nature 218, 12111214.

3. Fletcher, J. \& Huehns, E. R. (1967), Nature 215, 584586.

4. Harris, D. C. (1977), Biochim. Biophys. Acta 496, 563565.

5. Harris, D. C. \& Aisen, P. (1975), Biochem. 14, 262-268.

6. Princiotto, J. V. \& Zapolsky, E. J. (1975), Nature 255, 87-88.

7. Harris, D. C. \& Aisen, P. (1975), Nature 257, 821-823.

8. Awai, M., Chipman, B. \& Brown, E. B. (1975), J. Lab. Clin. Med. 85, 769-784. the Fe-complexing properties of NTA, so that not all the transferrin is saturated.

When monoferric transferrin, labelled at the B-site at high $\mathrm{pH}$, was dialyzed for 20 hours at $20^{\circ} \mathrm{C}$ against

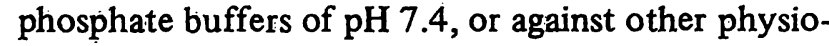
logical media in which iron uptake from transferrin into reticulocytes can take place (12), we observed, using isoelectric focussing, a shift in the iron distribution.

This raises the question as what happens with monoferric A- or B-site labelled transferrin, injected into the circulation or applied in vivo at $37^{\circ} \mathrm{C}$ and $\mathrm{pH} 7.4$. Our results indicate that within 0.5 hour at alkaline $\mathrm{pH}$, iron moves from the A-site to the B-site, so all conclusions about different physiological roles of $\mathrm{A}$ - and B-site and specific/non-specific uptake by cells from A- or B-site must be considered with great suspicion and criticism.

Not only before the incubation experiment, but also after the incubation with cells, the transferrin solutions should be inspected on the presence of monoferric Aor B-site labelled transferrin by isoelectric focussing.
9. Princiotto, J. V. \& Zapolsky, E. J. (1976), Biochim. Biophys. Acta 428, 766-771.

10. Lestas, A. N. (1976), Brit. J. Haematol., 32, 341-349.

11. Makey, D. G. \& Seal, U. S. (1976), Biochim. Biophys. Acta 453, 250-256.

12. Verhoef, N. J. \& van Eijk, H. G. (1975), Clin. Sci. Mol. Med. 48, 335-340.

13. Blakesley, R. W. \& Boezi, J. A. (1977), Anal. Biochem. 82 , 580-582.

14. Smith, I. (1968), Chromatography and Electrofocussing p. 267, Vol. II, 2. ed., William Heineman Ltd. (London).

15. Cannon, J. C. \& Chasteen, N. D. (1975), Biochemistry i4, 4573-4577.
Dr. H. G. van Eijk Dept. Chem. Pathol. Erasmus University Postbus 1738 Rotterdam The Netherlands 